
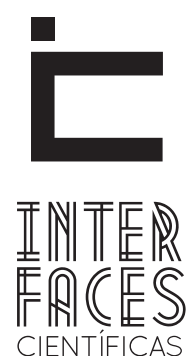

HUMANAS E SOCIAIS

\title{
RELAÇÕES ÉTNICO-RACIAIS: UMA ABORDAGEM ESCOLAR
}

\author{
ETHNIC-RACIAL RELATIONS: A SCHOOL APPROACH \\ RELACIONES ÉTNICO-RACIALES: UN ENFOQUE ESCOLAR
}

\section{RESUMO}

Este artigo configura-se como uma análise de base compreensiva interpretativa das relações étnico-raciais no contexto da educação escolar. Tem-se como objeto empírico a prática pedagógica e sua relação com a efetivação da Lei no 10.639/03. Assim, realizouse um estudo bibliográfico a partir das contribuições de Martins (2011), Munanga (2012), Gomes (2008), Hall (2011), que colaboraram para a compreensão da temática referente às relações étnico-raciais no contexto escolar. Dessa forma, objetiva conhecer a prática pedagógica desenvolvida na educação básica e as relações estabelecidas/construídas para a efetivação da Lei no 10.639/03, concernente à inserção do estudo da história e cultura afro-brasileira e africana nos currículos escolares. Para tanto, as fontes utilizadas constituem-se de natureza bibliográfica, com metodologia de cunho discursivo-interpretativo, a partir da problematização de tópicos correlatos, a saber: 0 dispositivo legal (Lei n 10.639/03 e sua efetivação no cotidiano escolar); aproximações necessárias entre práticas pedagógicas e a educação contextualizada.

\section{PALAVRAS-CHAVE}

Relações Étnico-Raciais. Prática Pedagógica. Contextualização. 


\section{ABSTRACT}

This article appears as an interpretive comprehensive baseline analysis of the ethnic-racial relations in the context of school education. This article appears as an interpretive comprehensive baseline analysis of the ethnic-racial relations in the context of school education. It has been as empirical object pedagogical practice and its relation to the effectiveness of Law No. $10,639 / 03$. Thus, there was a bibliographic study from Martins contributions (2011), Munanga (2012), Gomes (2008), Hall (2011), which contributed to the understanding of the issue related to ethnic-racial relations in the school context. Thus, objective know the pedagogical practice developed in basic education and the relationships established / constructed for the effectiveness of Law No. 10,639/03, concerning the inclusion of the study of history and african-Brazilian and African culture in school curricula. To do so, the sources used are made up of bibliographical, with discursive interpretative methodology, based on the questioning of related topics, namely: the legal provision (Law No. 10.639 / 03 and its implementation in everyday school life); necessary approaches between teaching practices and contextualized education.

\section{KEYWORDS}

Ethnic-Racial Relations. Pedagogical Practice. Contextualization.

\section{RESUMEN}

Este artículo se presenta como un análisis de base comprensiva interpretativa de las relaciones étnico-raciales en el contexto de la educación escolar. Se tiene como objetivo empírico la práctica pedagógica y su relación con la eficacia de la Ley $n^{0}$ 10.639/03. Por lo tanto, hubo un estudio bibliográfico a partir de las contribuciones de Martins (2011), Munanga (2012), Gomes (2008), Hall (2011), que contribuyeron a la comprensión de la cuestión referente a las relaciones étnico-raciales en el contexto escolar. Por lo tanto, se objetiva conocer la práctica pedagógica desarrollada en la educación básica y las relaciones que se establecen/construyen para la realización de la Ley 10.639/03, relativa a la inclusión del estudio de la historia y cultura afrobrasileña y africana en los programas escolares. Con ello, las fuentes utilizadas se componen de naturaleza bibliográfica, con la metodología interpretativa-discursiva, desde el cuestionamiento de temas relacionados, a saber: la disposición legal (Ley 10.639/03 y su aplicación en la vida escolar cotidiana); enfoques necesarios entre las prácticas de enseñanza y la educación contextualizada.

\section{PALABRAS CLAVE}

Relaciones étnico-raciales. La práctica pedagógica. Contextualización. 


\section{INTRODUCÇÃO: PRIMEIRAS APROXIMAÇÕES}

Este artigo resulta das inquietações e ensejos discutidos no projeto de pesquisa intitulado "As relações étnico-raciais expressas nas práticas pedagógicas: um estudo etnográfico no Colégio Municipal Antônio Marculino Vieira, Aguada Nova, Município de Lapão (BA)", que por sua vez tenciona discutir sobre a educação escolar com vistas à garantia do direito ao estudo e valorização da identidade cultural de matriz africana e afro-brasileira, por ainda apresentar dificuldades para o seu pleno desenvolvimento, considerando que,apesar da promulgação da Lei $n^{0} 10.639 / 03$, tornando obrigatório nos currículos escolares, o estudo da história e cultura afro-brasileira sua prática efetiva ainda é bastante incipiente.

A partir dessa obrigatoriedade, as unidades escolares passaram a apresentar projetos pedagógicos relacionados à temática africana, ou discutiram sobre eixos temáticos relacionados à identidade afro-brasileira, porém de maneira incipiente, pontual e, de certa maneira, folclorizada, faltando, assim, uma discussão mais aprofundada sobre a história e a cultura afro-brasileira. Essa percepção resulta de um olhar superficial e generalista da cultura escolar.

Cultura escolar que, por sua vez, necessita de um entendimento sério da sua abrangência e principalmente da sua vinculação com o comprometimento para com as práticas pedagógicas significativas, uma vez que

\begin{abstract}
[...] a cultura escolar se faz a partir de um múltiplo agenciamento de atitudes, valores, processos de ensino-aprendizagem, trocas culturais, etc. Isto conduz a um campo multidisciplinar da produção do saber científico e enriquece o olhar sobre a diversidade inerente às culturas escolares. (MONTEIRO, 2011, p. 220).
\end{abstract}

Com esse entendimento sobre a cultura escolar, a promulgação da Lei $n^{0} 10.639 / 03$, representou uma política pública comprometida com o respeito à diversidade brasileira, além de fomentar o estreitamento/ embricamento das relações culturais, principalmente no que se refere ao acesso ao capital cultural, como a educação escolar sistematizada e a elevação da autoestima dos sujeitos, em especial os afrodescendentes, por oportunizar, a partir de então, o conhecimento sobre sua história e dos seus ancestrais.

A partir dessa realidade, as políticas públicas são entendidas como o conjunto de ações/atividades desenvolvidas em prol da qualidade de vida de um grupo/coletividade. No bojo desse entendimento, como política pública de ação afirmativa, a Lei $n^{0}$ 10.639/03, desde a sua implantação, teve como objetivo "corrigir injustiças, eliminar discriminações e promover a inclusão social e a cidadania para todos/ as no sistema educacional brasileiro" (BRASIL, 2004, p. 5). Pensar a essência desse objetivo requer reflexão sobre as condições historicamente vivenciadas pela população afro-brasileira, o que tornou urgente desenvolver políticas públicas que atendessem às suas necessidades, buscando dessa forma superar os limites e dificuldades existentes.

As políticas públicas de ação afirmativa para os afrodescendentes têm fomentado, mesmo que lentamente, a superação da situação histórica vivenciada pelos afro-brasileiros, permitindo às atuais gerações possibilidades de inserção e permanência nos diversos espaços sociais, como no espaço das instituições escolares, especialmente as de nível superior, antes excludentes aos sujeitos afrodescendentes. Por exemplo, a institucionalização do sistema de cotas nas instituições de ensino e nas seleções públicas de trabatho representou e continua a representar um avanço significativo para a população.

Fazer valer a efetivação da Lei no 10.639/03 nos espaços escolares é tarefa crucial para a melhor qualidade de vida de todos. Essa tarefa consiste num exercício pertinente à coletividade, independente- 
mente de seu pertencimento étnico-racial, pois cultivar e promover o respeito à diversidade é obrigação de todos(as) aqueles(as) que almejam uma vida digna e justa com harmonia na convivência humana.

A garantia do pleno exercício do respeito às diferenças não se restringe tão somente à promulgação da lei, mas sim na sua efetivação no cotidiano das práticas pedagógicas das unidades escolares, bem como na oferta de formação continuada dos profissionais da educação, para que estes possam fortalecer as ações e atitudes de reconhecimento da cultura e das relações étnico-raciais de base africana no território brasileiro, pois:

\begin{abstract}
Reconhecer exige a valorização e respeito às pessoas negras, à sua descendência africana, sua cultura e história. Significa buscar, compreender seus valores e lutas, ser sensível ao sofrimento causado por tantas formas de desqualificação: apelidos depreciativos, brincadeiras, piadas de mau gosto sugerindo incapacidade, ridicularizando seus traços físicos, a textura de seus cabelos, fazendo pouco das religiões de raiz africana. Implica criar condições para que os estudantes negros não sejam rejeitados em virtude da cor da sua pele, menosprezados em virtude de seus antepassados terem sido explorados como escravos, não sejam desencorajados de prosseguir estudos, de estudar questões que dizem respeito à comunidade negra. (BRASIL, 2004, p. 12).
\end{abstract}

Portanto, propomos neste artigo compartilhar algumas inquietações referentes à maneira como a história e cultura afro-brasileira e africana é trabalhada nos espaços escolares, problematizando tais inquietações.

\section{DISPOSITIVO LEGAL: LEI № 10.639 E SUA EFETIVAÇ̃̃O NO COTIDIANO ESCOLAR}

Estudar a temática da história e cultura afro-brasileira nos espaços da educação formal, como nas escolas, por exemplo, é criar possibilidade(s) para a socialização das contribuições que africanos e afro-brasileiros tiveram na formação da sociedade brasileira, além de rever práticas e atitudes discrimi- natórias cometidas no decurso da história contra os africanos e afrodescendentes que tiveram, por muito tempo, seus direitos negligenciados, como a educação, especialmente em relação ao acesso e permanência nos espaços escolares.

A discussão sobre as Diretrizes Curriculares Nacionais para a Educação das Relações Étnico-Raciais e para o Ensino de História e Cultura Afro-Brasileira e Africana não tem constituído uma representação efetiva nas práticas pedagógicas cotidianas, ocorrendo, por vezes, ações isoladas ou práticas folclorizadas e pontuais.

Dessa forma, é salutar reconhecer que, de acordo com a Lei n 10.639/03, “Os conteúdos referentes à História e Cultura Afro-Brasileira serão ministrados no âmbito de todo o currículo escolar, em especial nas áreas de Educação Artística e de Literatura e História Brasileiras" (BRASIL, 2004, p. 35). Portanto, há que se reconhecer que o uso do termo em especial, não indica, somente ou exclusivamente, a temática em análise, pode permear todos os componentes curriculares, não se restringindo a responsabilidade tão somente aos professores de Educação Artística, Literatura e História Brasileiras.

Assim, torna-se oportuno questionar o modo, objetivos e estratégias adotadas no desenvolvimento das práticas pedagógicas escolares no que tange aos conteúdos da história e cultura afro-brasileira, pois efetivar práticas pedagógicas de maneira coerente relacionada a essa temática vai além da realização de atividades de celebração da cultura, inclui práticas de contextualização didático-pedagógicas no cotidiano da unidade escolar, imbricando-se na cultura escolar, de modo geral, das instituições escolares brasileiras, com destaque especial aos espaços escolares em que predomina o público afrodescendente.

Por conseguinte, o que se pretende não é simplesmente a inserção da História e Cultura Afro-Brasileira e Africana no currículo escolar, como já previsto em lei, mas o reconhecimento e valorização da história 
e cultura afro-brasileira como parte significativa da formação histórica da sociedade brasileira, haja vista que, por muito tempo, foi desconsiderada nas discussões e práticas escolares. "A questão da raça e da etnia não é simplesmente um 'tema transversal': ela é uma questão central de conhecimento, poder e identidade”, segundo Silva (2005, p. 102). Aliada a esta discussão, Hall (2011, p. 13) nos chama a atenção dizendo:

\begin{abstract}
A identidade plenamente unificada, completa, segura e coerente é uma fantasia. Ao invés disso, à medida que os sistemas de significação e representação cultural se multiplicam, somos confrontados por uma multiplicidade desconcertante e cambiante de identidades possíveis, com cada uma das quais poderíamos nos identificar - ao menos temporariamente.
\end{abstract}

As discussões em torno da categoria identidade devem incidir inicialmente pelo pressuposto da inexistência da unidade na identidade, mas a existência de um caráter plural e plástico, com fazer e refazer constante, nesse sentido, ao pensar em identidade africana ou afro-brasileira, suscita pensar na infinidade de culturas existentes entre os diversos povos do continente africano.

Sabemos hoje que as identidades culturais não são rígidas nem, muito menos, imutáveis. São resultados sempre transitórios e fugazes de processos de identificação. Mesmo as identidades aparentemente mais sólidas, como a de mulher, homem, país africano, país latino-americano ou país europeu, escondem negociações de sentido, jogos de polissemia, choques de temporalidades em constante processo de transformação, responsáveis em última instância pela sucessão de configurações hermenêuticas que de época para época dão corpo e vida a tais identidades. Identidades são, pois, identificações em curso. (SANTOS, 2006, p.135).

Dessa forma, pensar na população brasileira é pensar nas múltiplas identidades em curso de seu povo, que constitui a diversidade cultural de sua gente com suas peculiaridades e especificidades que, juntas ou não, se complementam formando a riqueza da cultura brasileira com sua pluralidade. "A Diversidade Cultural se realiza no humano, ao longo da História. E é nesse contexto que as relações raciais se configuram, constroem e reconstroem" (GOMES, 2008, p. 135).

No entanto, é ainda por vezes imprecisa essa compreensão a respeito da formação contínua da identidade como caracterizado por Hall, persistindo entre diversos grupos sociais e culturais o ensejo de reconhecimento da identidade de seu povo como algo já constituído, como uma identidade já formada, postura essa que pode ser representada pelas terminologias que fazem coro nas bandeiras de luta e reivindicação, exigindo/cobrando do outro, para com sua cultura: valorização, respeito, pertencimento, reconhecimento. 0 êxito preconizado em tais terminologias em relação à cultura e identidade de um povo não ocorrem por meio do movimento exterior-interior, mas perfazendo o caminho inverso, partindo do eu, da sua consideração para a conquista da valorização, respeito, pertencimento e reconhecimento do(s) outro(s).

Essa concepção ainda imprecisa sobre a construção da identidade cultural de um povo é percebível em determinadas situações em que o ideal da homogeneização da cultura desses grupos/povos é expresso por meio de posicionamentos que acirram o ideal etnocêntrico. Não reconhecendo que "a identidade é relacional. [...] A identidade é, assim, marcada pela diferença" (WOODWARD, 2011, p. 9), diferença essa que pode estar presente até mesmo dentro de um mesmo grupo cultural.

É no reconhecimento da diferença e no seu respeito que se fortalece a identidade de um povo. E, a esse respeito, a escola, com o desenvolvimento de práticas pedagógicas coerentes e consistentes, poderá fazer a diferença tão necessária na formação das crianças, adultos, jovens e idosos, colaborando para a construção da identidade.

\footnotetext{
Bourdieu, num de seus estudos, disse que a sociologia do conhecimento e da educação não tem prestado a devida atenção à relevante função de integração cultural da escola. A transmissão cultural efetuada pela escola é ao mesmo tempo uma recriação cultural e,
} 
por isso, "parece ingênuo querer ignorar que a escola, pela própria lógica de seu funcionamento, modifica o conteúdo e o espírito da cultura que transmite e, sobretudo, cumpre a função expressa de transformar o legado coletivo em um inconsciente individual e comum. (AZANHA, 1990-1991, p. 68).

Uma vez que, por tanto tempo, o estudo das relações culturais dos grupos minoritários foram negligenciados por conta da valorização e predominância da cultura dos grupos dominantes, nessa perspectiva resulta a necessidade urgente de repensar as práticas pedagógicas desenvolvidas nas instituições escolares.

Nesse contexto, estudar como as práticas pedagógicas vêm sendo desenvolvidas, em sintonia com o reconhecimento da cultura existente nas comunidades remanescentes de quilombo, é antes de tudo reconhecer que a cultura de matriz africana foi, por muito tempo, negada, desvalorizada nos meios sociais, dentre estes, a escola, e que precisa ser repensada e melhor trabalhada e reconhecida, a fim de que os(as) alunos(as) possam conhecer a sua história e sua cultura, possibilitando o novo pensar sobre as mesmas, tendo em vista que

A educação constitui-se um dos principais ativos e mecanismos de transformação de um povo e é papel da escola, de forma democrática e comprometida com a promoção do ser humano na sua integralidade, estimular a formação de valores, hábitos e comportamentos que respeitem as diferenças e as características próprias de grupos e minorias. Assim, a educação é essencial no processo de formação de qualquer sociedade e abre caminhos para a ampliação da cidadania de um povo. (BRASIL, 2004, p. 7).

De acordo com o preconizado na Lei $n^{0}$ 10.639/03, faz-se necessário uma prática pedagógica que apresente em seu cerne o trabalho, na perspectiva da valorização da identidade, a partir das diferenças, permitindo aos sujeitos do processo de ensino-aprendizagem o convívio dialógico e respeitoso entre seus pares, sejam estes pertencentes aos seus grupos culturais ou não, visto que o sujeito social participa de vários grupos, sendo, portanto, um sujeito plural, a partir da cultura escolar que é desenvolvida nas instituições escolares. A cultura escolar desempenha, nesse sentido, uma importante contribuição, uma vez que constitui

[...] um conjunto de normas que definem conhecimentos a ensinar e condutas a inculcar, e um conjunto de práticas que permitem a transmissão desses conhecimentos e a incorporação desses comportamentos; normas e práticas coordenadas a finalidades que podem variar segundo épocas (finalidades religiosas, sociopolíticas ou simplesmente de socialização). (JULIA, 2001, p. 10).

A necessidade de tornar acessível o conhecimento sobre a diversidade étnico-racial existente entre os povos e sujeitos que fazem acontecer o dia a dia do universo escolar de inúmeras instituições brasileiras é que remete ao comprometimento, especialmente entre os docentes, de provocar e promover a interação consciente e sistemática entre o currículo, a cultura escolar e a(s)identidade(s), numa dinâmica que favoreça a superação da situação historicamente enfrentada pelos sujeitos pertencentes aos grupos étnicos tidos como minoritários.

Os docentes, desta feita, estariam possibilitando uma concepção de currículo que evidencie a vivência dos alunos em sua concretude, pois

O currículo é lugar, espaço, território. 0 currículo é relação de poder. 0 currículo é trajetória, viagem, percurso. O currículo é autobiografia, nossa vida, curriculum vitae: no currículo é texto, discurso, documento. 0 currículo é documento de identidade. (SILVA, 2005, p. 150).

Sendo o currículo documento de identidade, as unidades escolares, em seu exercício docente, não poderão desconsiderar a realidade predominante em seus alunos(as). Mesmo porque remeteria ao processo de descontextualização da sua práxis; perspectiva que muitos teóricos e pesquisadores tencionam combater, por considerar que toda práxis, toda ação é intencional e emerge de uma situação de valores, de conflitos, de tensões e, muitas vezes, de interesses. 


\section{APROXIMAÇ̃̃̃ES NECESSÁRIAS ENTRE PRÁTICAS PEDAGÓGICAS E A EDUCAÇÃO CONTEXTUALIZADA}

As práticas pedagógicas baseadas na colonialidade eurocêntrica por muito tempo predominaram no cenário educacional brasileiro, caracterizadas pelo caráter universal, com conhecimento generalista no cumprimento das bases comuns que dão sustentação à trama do currículo tradicional.

A predominância da colonialidade eurocêntrica permitiu, especialmente entre os participantes do processo educativo escolar,

\begin{abstract}
[...] produzir e difundir sua auto imagem ao mundo, se baseou também em princípios como os de universalidade, racionalidade, normalidade, por exemplo, para definir quais modos de fazer, pensar, sentir, dizer, agir, viver, eram mais legítimos do que outros, por sua vez, declarados incorretos, inapropriados, supersticiosos. (MARTINS, 2011, p. 48).
\end{abstract}

Com o passar do tempo, surgiram críticas a respeito da colonialidade eurocêntrica e do caráter generalista das práticas pedagógicas, evidenciando a perspectiva pluralista da educação, pois educação é vida, é dinamismo, é movimento, e a educação escolar passou gradativamente a construir novos contornos e perspectivas, como, por exemplo, a educação contextualizada.

No meu entendimento, "a educação contextualizada" se associa aos processos de rompimento com a narrativa hegemônica, eurocêntrica, branca, macha, cristã, racionalista e capitalista - ou, se não isto, pelo menos associada aos processos de rompimento com as narrativas de algum modo exógenas às formas de vida particulares, com as quais tais narrativas hegemônicas não dialogam e acabam tomando como seus "Outros". Chamamos tais narrativas hegemônicas de coloniais, tendo elas predominado na experiência educacional não apenas no Brasil, mas em diversos outros pontos do globo. (MARTINS, 2011, p. 47).
A educação escolar, na perspectiva contextualizada, privilegia a realidade do aluno, como ponto de partida para a construção e socialização do conhecimento, realidade essa, entendida como o seu modo de vida, seus costumes, hábitos, tradições, culturas, enfim, tudo aquilo que compreende o contexto sócio-histórico do(a) aluno(a) e da comunidade em que a escola está inserida, uma vez que a escola não está assentada sob um território amorfo, neutro, sem vida, passivo a receber as contribuições de um "conhecimento privilegiado" deslocado de sua realidade.

\begin{abstract}
Fazer Educação Contextualizada é praticar uma Educação, que parta da realidade dos sujeitos; parta da riqueza, dos limites e da problemática geral dos contextos de vida das pessoas. Mas, não é para ficar dando voltas nisso. É para produzir conhecimento sofisticado, baseado em trabalhos de pesquisa, em estudos, em tematizações e sistematizações, em problematizações fundamentadas e em ações concretas, amparadas pelos conhecimentos gerados num itinerário pedagógico, partindo sempre da teoria à prática e vice-versa. Assim sendo, todo trabalho de Educação Contextualizada supõe um itinerário pedagógico que: a) parte do conhecimento desta realidade; b) problematiza esta realidade, excedendo o conhecimento empírico inicial; e c) organiza um processo de transformação desta realidade, a partir do novo conhecimento produzido sobre ela. (MARTINS, 2011, p. 58).
\end{abstract}

Diante do exposto, não se tenciona aqui desconsiderar a socialização do conhecimento historicamente construído, mas pretende potencializá-lo, por meio da prática pedagógica contextualizada. Essa perspectiva reconhece a riqueza do trabalho a partir da valorização da(s) identidade(s), que por muito tempo teve seu reconhecimento e estudo negligenciados em favor de uma identidade dominante, ou seja, a identidade do colonizador.

Esse movimento instiga a equipe docente a organizar o trabalho pedagógico com vistas à dinamicidade em vigor, bem como o fomento da necessidade da formação continuada, que thes dê suporte para fundamentar e subsidiar a proposta de trabalho, pois essa perspectiva de trabalho suscita o encorajamen- 
to, comprometimento e reconhecimento constante das especificidades que os sujeitos do processo educativo apresentam.

Se o processo de construção da identidade nasce a partir da tomada de consciência das diferenças entre "nós" e os "outros", não creio que o grau dessa consciência seja idêntico entre todos os negros, considerando que todos vivem em contextos socioculturais diferenciados. Partindo desse pressuposto, não podemos confirmar a existência de uma comunidade identitária cultural entre grupos de negros que vivem em comunidades religiosas diferentes, por exemplo, os que vivem em comunidades de terreiros de candomblé, de evangélicos ou de católicos, etc. em comparação com a comunidade negra militante, altamente politizada sobre a questão do racismo, ou com as comunidades remanescentes dos quilombos. (MUNANGA, 2012, p. 11).

Nesse sentido, a escola representa um espaço privilegiado de interação das diversidades culturais, promovendo a contínua inserção e interação do(a) aluno(a) em diversos subgrupos, que remete a uma identidade distinta, como, por exemplo, o grupo da capoeira, o grupo de dança, o grupo de futebol, o grupo dos alunos, o grupo de professores, o grupo de mulheres, o grupo de homens, bem como a participação concomitante de um sujeito em outro(s) grupo(s). Tais participações/interações favorecem o desenvolvimento da consciência política, social e cultural a respeito da identidade e diferença entre os povos.

O envolvimento gerado a partir da participação dos sujeitos em diversos grupos ou movimentos sociais leva-os a desenvolverem o senso crítico e o desejo de superação dos entraves existentes, como pode ser verificado no posicionamento de Gomes (2008, p. 138) quando assevera que:

Os negros, por meio da sua vivência cotidiana, das lutas do movimento negro brasileiro e das ações dos grupos culturais, politizam a própria história e, ao fazerem isso, politizam a história do Brasil. Eles o fazem quando denunciam o racismo, quando criam práticas de resistência, quando dão publicidade às suas práticas culturais, quando lutam por direitos sociais e identitários, quando retiram as práticas culturais de matriz africana e afro-brasileira do lugar do exotismo onde elas, lamentavelmente, ainda são colocadas.

Dessa forma, há que se pensar sobre a importância e a influência da participação em grupos de militância para o processo de constituição do ser social no contexto da diversidade e de produção da diferença, dentro de um mesmo grupo étnico, diferença essa marcada por meio da possibilidade de todo e qualquer sujeito participar de quantos grupos sociais for de seu interesse.

Quando aqui se advoga sobre a importância da participação em grupos e movimentos sociais para a melhoria da qualidade de vida e sua constituição social há que se entender o caráter plural e polissêmico desses movimentos.

De acordo com Souza (2010, p. 4), o professor, ao desenvolver a prática pedagógica na perspectiva da educação contextualizada, "deve emocionar a muitos; sem emoção não há paixão, e sem paixão não há compromisso. Contra isso existe o pensamento dominante". A contribuição de Souza (2010, p. 4) para com a educação contextualizada nos remete à reflexão sobre a necessidade de desenvolver práticas pedagógicas que estimulem a criticidade e o reconhecimento da diversidade presente na sociedade quando salienta que

A (neo) colonização cultural esteriliza a diversidade do pensamento crítico e criativo local e semeia o pensamento único, universal, do dominador. 0 problema da educação descontextualizada é que foi concebida para levar-nos a pensar como Eles para sermos como Eles [...].(Grifo do autor).

A prática pedagógica resulta nesse diálogo constante sobre que tipo de sujeito a escola tenciona contribuir em formar. Para as unidades escolares, cujo público seja predominantemente considerado afrodescendente, a ênfase no trabalho da criticidade deve ser mais efetivo, por ser "crucial que o/a aluno/a observe como em sua identidade se misturam aspectos que podem ser alvos de discriminação e opressão, assim como 
aspectos associados a grupos que têm dominado e explorado outros" (MOREIRA; CÂMARA, 2008, p. 47).

Nesse processo, a prática pedagógica que vislumbra respeitar as matrizes culturais e sociais dos(as) seus(suas) alunos(as) deve sempre questionar e refletir a proposta curricular da unidade escolar em questão, com os mediadores do processo educativo, sempre indagando sobre essas práticas com vistas a uma ação pedagógica comprometida com a elevação da autoestima dos sujeitos reconhecendo suas identidades e diferenças. Nesse diálogo, Moreira e Câmara (2008, p. 44) chamam a nossa atenção, afirmando:

Será que em nossas escolas e em nossas salas de aula ainda caminhamos, com nossas práticas, na direção de anular aspectos das identidades dos/as estudantes? Será que os processos de homogeneização que muitas vezes promovemos, por meio do currículo, dos procedimentos didáticos, das relações pedagógicas e da avaliação, contribuem, de algum modo, para consolidar as relações de poder que atravessam as diferenças presentes no seio do nosso alunado?

Reitera-se que a prática pedagógica configura-se no exercício da sensibilidade, envolvimento e comprometimento entre alunos(as) e professores(as) no trato das relações de ensino e aprendizagem em que o respeito e valorização das diferenças se tornem uma prática efetiva, vivenciada por todos os copartícipes do sistema educacional. No que Freire (1996, p. 30) defende que "ensinar exige respeito aos saberes dos educandos". Esse respeito pode ser caracterizado pelo que é defendido aqui, enquanto educação contextualizada, em que a prática pedagógica reconhece os saberes dos educandos na construção da sua proposta de trabalho.

\section{POSSÍVEIS CONSIDERAÇÕES FINAIS}

Reconhecendo, portanto, que o trabalho pedagógico baseado na premissa de respeito dialógico para com as diversas culturas existentes no seio da unidade escolar não é tarefa fácil, nem passível de ser efe- tivada repentinamente, sem um esforço legítimo de seus copartícipes, Stoer e Cortesão (1999, s.p APUD MOREIRA; CÂMARA, 2008, p. 46) ainda contribuem nesse entendimento ao aludir que:

\begin{abstract}
0 "arco-íris de culturas" em nossas escolas faz com que o trabalho docente seja mais complexo, mais difícil mesmo. Demanda considerar como se faz viável despertar o interesse de alunos/as tão diferentes, atender às especificidades de distintos grupos, problematizar relações de poder que justificam situações de opressão, assim como facilitar a aprendizagem de todos/as os/as estudantes. Ao mesmo tempo, a multiplicidade de manifestações culturais e de identidades torna a sala de aula rica, plural, estimulante, desafiante.
\end{abstract}

Esses saberes diversos advindos com os educandos poderiam ser fortalecidos e estar presentes nas práticas pedagógicas desenvolvidas nas unidades escolares, visando à apreensão e compreensão dessa riqueza que constitui a diversidade cultural brasileira, propiciando a ampliação do conhecimento da capacidade dialógica e a relação intrínseca entre os saberes locais e os saberes globais.

De acordo com Libâneo (1992, p. 11),

\begin{abstract}
Aprender é um ato de conhecimento da realidade concreta, isto é, da situação real vivida pelo educando, e só tem sentido se resulta de uma aproximação crítica dessa realidade. 0 que é aprendido não decorre de uma imposição ou memorização, mas do nível crítico de conhecimento, ao qual se chega pelo processo de compreensão, reflexão e crítica.
\end{abstract}

Portanto, a prática pedagógica, na perspectiva da educação contextualizada, representa a continuidade da luta por uma educação popular que valoriza o conhecimento inerente às populações tidas minoritárias da sociedade, que, por influências de ordem política e social, tornaram-se marginalizadas. Diante dessa conjectura, a educação para as relações étnico-raciais, ganha força e espaço, onde historicamente inúmeras pessoas foram e ainda são vítimas da discriminação e preconceito, por conta de, entre outros motivos, a escola ter promovido uma prática pedagógica 
excludente e discriminatória para com a população africana e afro-brasileira, sobre tal situação é que se faz necessário lutar e combater.

\section{REFERÊNCIAS}

AZANHA, José Mário Pires. Cultura escolar brasileira: um programa de pesquisa. Revista USP, São Paulo, n. 8, dez./fev. 1990-1991. p.65-69. Disponível em: <http://www3.fe.usp.br/secoes/inst/novo/acervo_ jmpa/PDF_SWF/158.pdf>. Acesso em: 24 ago. 2014.

BRASIL. Ministério da Educação. Diretrizes

curriculares nacionais para a educação das relações étnico-raciais e para o ensino de história e cultura Afro-brasileira e africana. Brasília, DF, 2004.

FREIRE, Paulo. Pedagogia da autonomia: Saberes necessários à prática educativa. São Paulo: Paz e Terra, 1996.

GOMES, Nilma Lino. Diversidade étnico-racial e a educação brasileira. In: BARROS, José Márcio (Org.). Diversidade cultural da proteção à promoção. Belo Horizonte: Autêntica, 2008. p.133-145.

\section{HALL, Stuart. A identidade cultural na pós-} modernidade. 11.ed. Rio de Janeiro: DP\&A, 2011.

JULIA, Dominique. A Cultura Escolar como Objeto Histórico. Revista Brasileira de História da

Educação, n.1, jan./jun. 2001. p. 9-43. Disponível em: <file:///c:/Users/Cliente/Downloads/273-846-1PB\%20(1).pdf>. Acesso em: 29 set. 2009.

LIBÂNEO, José Carlos. Tendências pedagógicas na prática escolar. In: LIBÂNEO, José Carlos.
Democratização da escola pública: A pedagogia críticosocial dos conteúdos. São Paulo: Loyola, 1992. p.19-44.

MARTINS, Josemar da Silva. Educação

Contextualizada: da teoria à prática. In: REIS, Edmerson dos Santos; CARVALHO, Luzineide Dourado. Educação Contextualizada: Fundamentos e Práticas. Juazeiro: UNEB, 2011. p.45-63.

MONTEIRO. Eliana de Barros. Etnografia, culturas escolares e antropologia crítica. 2011. Disponível em: <http://www.cchla.ufrn.br/interlegere/09/ pdf/09es13.pdf>. Acesso em: 27 out. 2014.

MOREIRA, Antônio Flávio; CÂMARA, Michelle Januário. Multiculturalismo: Diferenças culturais e práticas pedagógicas. In: Reflexões sobre currículo e identidade: implicações para a prática pedagógica. Petrópolis: Vozes, 2008. p.38-66.

SANTOS, Boaventura de Sousa. Pela mão de Alice: o social e o político na pós-modernidade. 11. ed. São Paulo: Cortez, 2006.

SILVA, Tomaz Tadeu da. Documentos de identidade: uma introdução às teorias do currículo. 2.ed. Belo Horizonte: Autêntica, 2005.

\section{SOUZA, José de Souza. Aridez mental, problema} maior: Contextualizar a educação para construir o 'dia depois do desenvolvimento’ no Semi-árido brasileiro. Disponível em: <http://www.ppgesa.uneb.br/arquivos/ Aridez\%20Mental.pdf $>$. Acesso em: 27 out. 2014.

WOODWARD, Kathryn. Identidade e diferença: uma introdução teórica e conceitual. In: SILVA, Tomaz Tadeu (Org.). Identidade e diferença: a perspectiva dos estudos culturais. 10.ed. Petrópolis: Vozes, 2011. p.7-72. 
1. Mestranda em Educação e Diversidade pela Universidade do Estado da Bahia - UNEBCampus IV - Jacobina,integrante da linha II Cultura escolar, docência e diversidade do Programa de Pós-Graduação stricto sensu, Mestrado Profissional em Educação e Diversidade. E-mail: ainatpires@bol.com.br 2. Pós-doutora em História pela Universidade de Lisboa UL-PT. Professora Titular Universidade do Estado da Bahia - UNEB; Professora do Programa de Mestrado em História Regional e Local - UNEB - Campus V - Santo Antônio de Jesus e do Programa de Mestrado Profissional em Educação e DiversiAceito em: 31 de Agosto de 2015 dade da UNEB - Campus IV - Jacobina. E-mail: carmelia15@hotmail.com 